\title{
Recurrent pancreatitis in the setting of gallbladder agenesis, ansa pancreatica, Santorinicoele and eventual intraductal papillary mucinous neoplasia (IPMN)
}

\author{
Sun Woo Lee ${ }^{1,2}$, Caroline Jane Davidson ${ }^{2,3}$, YinHiew Kia ${ }^{2,4}$, Ben Devereaux ${ }^{2,4}$, Savio Godinho ${ }^{2,5}$, \\ Mark Appleyard ${ }^{4}$, Nicholas O'Rourke ${ }^{2,6}$, and Manju Dashini Chandrasegaram ${ }^{2,3}$ \\ ${ }^{1}$ Princess Alexandra Hospital, ${ }^{2}$ School of Medicine, The University of Queensland, ${ }^{3}$ Department of General Surgery, \\ The Prince Charles Hospital, ${ }^{4}$ Department of Gastroenterology, Royal Brisbane and Woman's Hospital, ${ }^{5}$ Department \\ of Radiology, The Prince Charles Hospital, ${ }^{6}$ Department of HPB Surgery, Royal Brisbane and Woman's Hospital, \\ Brisbane, Queensland, Australia
}

\begin{abstract}
Gallbladder agenesis is a rare condition. Patients with gallbladder agenesis can present with biliary type symptoms and rarely pancreatitis. We present the case of a 35-year-old gentleman who was admitted and treated for recurrent pancreatitis on a background of gallbladder agenesis, ansa pancreatica and Santorinicoele. He has had several admissions with pancreatitis and has had multiple imaging modalities during these admissions which we delineate. We discuss this rare anatomical variant and describe the course and management of his illness leading up to his eventual diagnosis of intraductal papillary neoplasia (IPMN). (Ann Hepatobiliary Pancreat Surg 2020;24:381-387)
\end{abstract}

Key Words: Gallbladder agenesis; Santorinicoele; Ansa pancreatica; Recurrent pancreatitis; Intraductal papillary neoplasia; IPMN

\section{INTRODUCTION}

Gallbladder agenesis is a rare condition. Patients are usually asymptomatic but they can present with biliary colic-type symptoms. Ansa pancreatica is a rare communication between the dorsal pancreatic duct and the minor papilla and can cause pancreatitis by virtue of impaired drainage of the main pancreatic duct through the minor papilla. Santorinicoele is a cystic dilatation of the duct of Santorini. Santorinicoele is normally associated with pancreas divisum with only a small number of cases reported without coexistent pancreas divisum. There is debate as to whether Santorinicoele is a congenital or acquired pathology. Recurrent pancreatitis can be associated with a Santorinicoele but this is typically in the group of patients who have pancreas divisum.

This is a rare case of a patient with recurrent pancreatitis on a background of gallbladder agenesis, ansa pancreatica and a Santorinicoele without pancreatic divisum who eventually in the course of follow-up is discovered to develop an intraductal papillary mucinous neoplasia (IPMN).

\section{CASE}

We present the case of a 35-year-old man who was admitted via our emergency department with epigastric pain and vomiting (Episode A, July 2017) (Table 1). He described progressive epigastric pain and discomfort over the previous three days. He described the pain as similar, but more severe than previous episodes of pain suffered over the last three years of mild pancreatitis. Magnetic resonance cholangiopancreatography (MRCP) had revealed absent gallbladder with unusual pancreatic ductal anatomy (Fig. 1).

His background history included gastro-oesophageal re-

Received: January 10, 2020; Revised: May 4, 2020; Accepted: May 7, 2020

Corresponding author: Manju Dashini Chandrasegaram

Department of General Surgery, The Prince Charles Hospital, 627 Rode Rd, Chermside, Brisbane, Queensland 4032, Australia Tel: +61-7-3139-4000, Fax: +61-7-3139-4883, E-mail: m.chandrasegaram@uq.edu.au

Copyright (C) 2020 by The Korean Association of Hepato-Biliary-Pancreatic Surgery

This is an Open Access article distributed under the terms of the Creative Commons Attribution Non-Commercial License (http://creativecommons.org/ censes/by-nc/4.0) which permits unrestricted non-commercial use, distribution, and reproduction in any medium, provided the original work is properly cited. Annals of Hepato-Biliary-Pancreatic Surgery - pISSN: 2508-5778 - elSSN: 2508-5859 
Table 1. Timeline and course of clinical presentation, procedures and relevant imaging

\begin{tabular}{|c|c|c|}
\hline Episode & Date & Presentation or procedure \\
\hline Episode A & July 2017 & $\begin{array}{l}\text { Pancreatitis and jaundice which settled - 9-day admission } \\
\text { MRCP and HIDA- Absent gallbladder, dilated minor duct to } 8 \mathrm{~mm} \text {, ansa pancreatica seen. } \\
\text { Dilated bile duct suggestive of choledochocoele }\end{array}$ \\
\hline Episode B & Aug 2017 & Outpatient appointment - resolution of jaundice \\
\hline Episode $\mathrm{C}$ & Jan 2018 & $\begin{array}{l}\text { ERCP, biliary and pancreatic duct sphincterotomy, main PD swept with balloon and stented } \\
\text { Unable to cannulate minor papilla }\end{array}$ \\
\hline Episode D & Jan 2018 & ERCP, removal of pancreatic duct stent \\
\hline Episode E & Nov 2018 & $\begin{array}{l}\text { Mild pancreatitis - 5-day admission with fevers and rigors for one day, no jaundice, treated } \\
\text { with antibiotics } \\
\text { MRCP Dilated ansa pancreatica. New pneumobilia related to previous sphincterotomy. Interval } \\
\text { normalisation of pancreatic duct. }\end{array}$ \\
\hline Episode F & Dec 2018 & Mild pancreatitis 2-day admission \\
\hline Episode G & Feb 2019 & ERCP sphincterotomy of minor papilla, pancreatic duct trawled and stented \\
\hline Episode $\mathrm{H}$ & March 2019 & Endoscopy and removal of pancreatic duct stent \\
\hline Episode I & July 2019 & Mild pancreatitis 5-day admission without jaundice \\
\hline Episode $\mathrm{J}$ & Aug 2019 & Mild pancreatitis 2-day admission without jaundice \\
\hline Episode $\mathrm{K}$ & Sept 2019 & $\begin{array}{l}\text { MRCP showed resolution of pancreatitis, stable dilatation of main bile duct, slight increase } \\
\text { in size of main pancreatic duct to } 5 \mathrm{~mm}\end{array}$ \\
\hline Episode L & Jan 2020 & Mild pancreatitis - one day admission \\
\hline Episode $\mathrm{M}$ & Feb 2020 & $\begin{array}{l}\text { Endoscopic ultrasound showed moderate chronic pancreatitis with pancreatic duct dilatation to } \\
6 \mathrm{~mm} \text { in the pancreatic head. Hyperechoic material within the duct of Santorini suggestive } \\
\text { of mucin. Prominent minor papilla exuded mucinous material. }\end{array}$ \\
\hline Episodes $\mathrm{N}$ & Feb 2020 & Three admissions for pancreatitis for 2 days; 2 days and 3 days respectively \\
\hline Episode $\mathrm{O}$ & March 2020 & $\begin{array}{l}\text { ERCP and spyglass into main pancreatic duct with visualisation of mucin and intraductal papil- } \\
\text { lary projections were seen within the pancreatic head and neck consistent with intraductal } \\
\text { papillary mucinous neoplasia (IPMN) }\end{array}$ \\
\hline
\end{tabular}

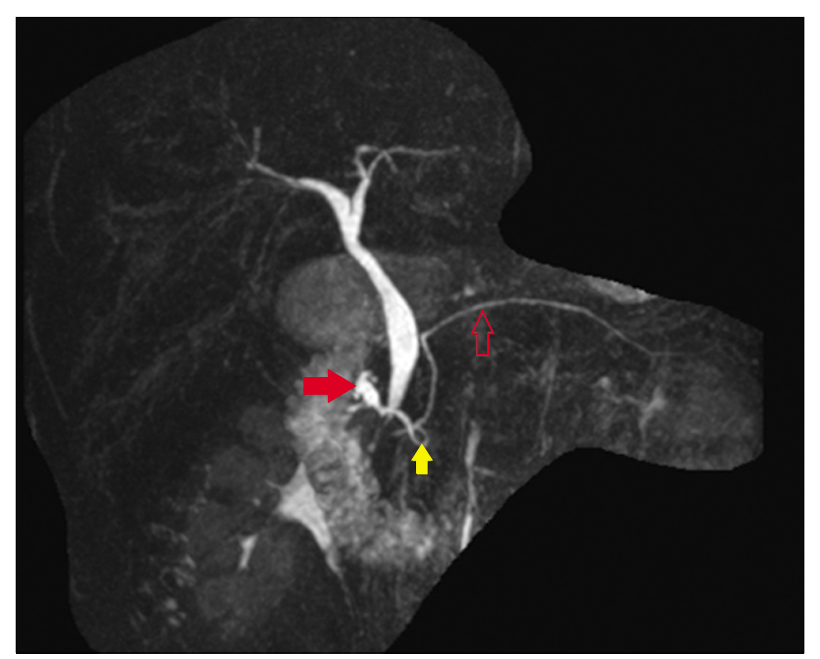

Fig. 1. Magnetic Resonance Cholangiopancreatography (MRCP) image confirming an absent gallbladder and defining the biliary anatomy. The main pancreatic duct (hollow red arrow) is shown. There is a dilated duct of Santorini draining into the minor papilla (solid red arrow) and an ansa pancreatica (yellow solid arrow) connecting the main pancreatic duct and duct of Santorini. flux disease. He took regular pantoprazole and was allergic to both cephalexin and ciprofloxacin which had previously caused anaphylactic reactions. He stopped smoking a year ago and had occasional alcohol.

On examination, he was jaundiced and his abdomen was soft but mildly tender in the epigastrium with no obvious masses. His lipase was elevated at $3670 \mathrm{U} / \mathrm{L}$ (reference $<60 \mathrm{U} / \mathrm{L}$ ). His liver function tests were deranged as follows: Bilirubin $98 \mu \mathrm{mol} / \mathrm{L}$ (reference $<20$ $\mu \mathrm{mol} / \mathrm{L}$ ), gamma-glutamyl transpeptidase (GGT) $309 \mathrm{U} / \mathrm{L}$ (reference $<55 \mathrm{U} / \mathrm{L}$ ), alkaline phosphatase (ALP) 244 $\mathrm{U} / \mathrm{L}$ (reference 30-110 U/L), alanine aminotransferase (ALT) $435 \mathrm{U} / \mathrm{L}$ (reference range $<45 \mathrm{U} / \mathrm{L}$ ) and aspartate aminotransferase (AST) $488 \mathrm{U} / \mathrm{L}$ (reference range $<35$ $\mathrm{U} / \mathrm{L}$ ). His $\mathrm{Ca} 19.9$ and alpha-fetoprotein were normal.

His current presentation was unusual compared to his previous presentations as he was jaundiced for the first time. CT scan of his abdomen revealed a heterogenous and oedematous pancreas with a prominent pancreatic duct of $3 \mathrm{~mm}$ and peripancreatic fat stranding and fluid extending to the pelvis (Fig. 2). A hepatobiliary iminodi- 

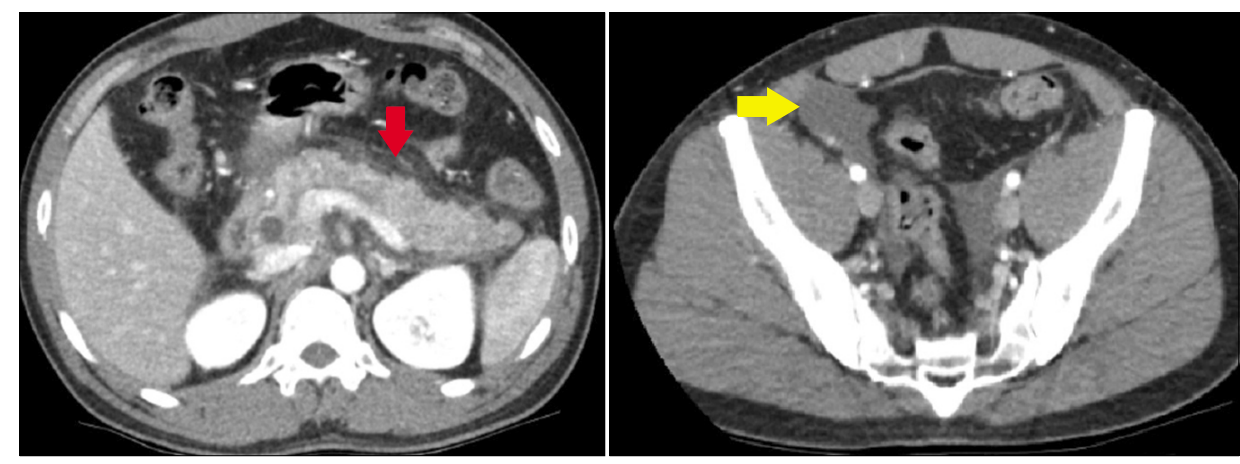

Fig. 2. Computed tomography (CT) of the abdomen showing pancreatitis with peripancreatic fat stranding (red arrow) with free fluid extending to the pelvis (yellow arrow).

acetic acid (HIDA) scintigraphy scan also confirmed gallbladder agenesis with normal emptying of bile from the bile duct into the bowel.

We performed an MRCP which revealed a bulky pancreas with diffuse peripancreatic fat stranding consistent with diffuse interstitial oedematous pancreatitis. The MRCP also revealed mild central intrahepatic biliary duct dilation, with common bile duct (CBD) measuring $8 \mathrm{~mm}$ at the porta hepatis, increasing to $15 \mathrm{~mm}$ at the mid CBD with smooth distal tapering in the pancreatic head. The appearance was that of a Type 1 choledochal cyst. There were no filling defects or stones within the bile duct. There was focal dilatation of the minor pancreatic duct of Santorini to $8 \mathrm{~mm}$ with multiple side branch ducts draining into this focal duct dilatation. The minor papilla appeared to be bulging raising the possibility that this was a Santorinicoele. A variation of his pancreatic duct configuration was evident with a reverse S-shape configuration to the duct of Santorini called ansa pancreatica (Fig. 3). This ansa pancreatica was a rare communication between the dorsal pancreatic duct and the minor papilla. The patient was managed with a brief period of gut rest and intravenous fluids. His jaundice and abdominal pain improved over the next few days and he was discharged.

On review in the clinic a month later he had been well with no further abdominal pain and he was no longer jaundiced (Episode B, Aug 2017). His liver function tests had improved: Bilirubin $25 \mu \mathrm{mol} / \mathrm{L}$ (reference $<20 \mu \mathrm{mol} / \mathrm{L}$ ), GGT $150 \mathrm{U} / \mathrm{L}$ (reference <55 U/L), ALP $100 \mathrm{U} / \mathrm{L}$ (reference 30-110 U/L), and ALT $101 \mathrm{U} / \mathrm{L}$ (reference $<45$ $\mathrm{U} / \mathrm{L}$ ). A follow-up MRCP three months later showed a significantly dilated ansa pancreatica including its side branches in the pancreatic head.

The patient underwent an outpatient endoscopic retrograde cholangiopancreatography (ERCP) approximately

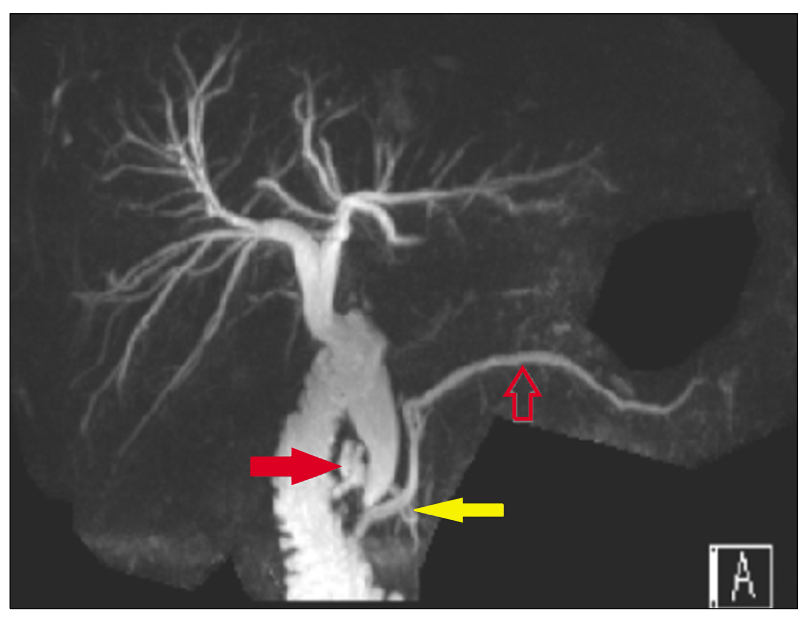

Fig. 3. Magnetic Resonance Cholangiopancreatography (MRCP) image showing mild intrahepatic duct dilatation and a dilated common bile duct which measures $8 \mathrm{~mm}$ at the porta hepatis and $15 \mathrm{~mm}$ at the mid CBD with smooth distal tapering. The main pancreatic duct (hollow red arrow) is prominent at 3 $\mathrm{mm}$, there is a Santorinicoele (solid red arrow) draining into minor papilla and an ansa pancreatica (yellow solid arrow) between the main pancreatic duct and Santorinicoele which is more prominent and dilated compared to Fig. 1 which was an MRCP done the month prior.

six months following his admission when his pancreatitis had settled both clinically and on imaging (Episode C, Jan 2018). He underwent a sphincterotomy and the major papilla was patulous with fluid suspicious for mucin at the pancreatobiliary orifice. The main pancreatic duct was deeply cannulated. The main pancreatic duct in the head of the pancreas contained an ovoid mobile filling defect thought to be suggestive of mucin. A $5 \mathrm{~mm}$ pancreatic duct sphincterotomy was performed. The main pancreatic duct was swept with an $8.5 \mathrm{~mm}$ balloon starting at the pancreatic duct in the body of the pancreas to evaluate this mobile filling defect. A 5 French by $8 \mathrm{~cm}$ plastic stent was placed into the pancreatic duct and there was only clear fluid flowing through the stent. The entire main bile duct was moderately dilated with no intraductal filling de- 
fects seen. A $6 \mathrm{~mm}$ biliary sphincterotomy was made and there was no post-sphincterotomy bleeding. The minor papilla was identified with a bulge in the region. However, despite multiple attempts made at cannulating the accessory duct of Santorini via the minor papilla, this was unsuccessful.

Despite the uncomplicated ERCP, the patient presented to the emergency department the following day with epigastric pain and nausea. His presentation was consistent with an episode of acute post-ERCP pancreatitis and his liver function tests showed moderate elevations: Bilirubin $81 \mu \mathrm{mol} / \mathrm{L}$ (reference $<20 \mu \mathrm{mol} / \mathrm{L}$ ), GGT $371 \mathrm{U} / \mathrm{L}$ (reference $<55 \mathrm{U} / \mathrm{L}$ ), ALP $90 \mathrm{U} / \mathrm{L}$ (reference 30-110 U/L), ALT $337 \mathrm{U} / \mathrm{L}$ (reference < $45 \mathrm{U} / \mathrm{L}$ ) and AST $244 \mathrm{U} / \mathrm{L}$ (reference $<35 \mathrm{U} / \mathrm{L}$ ). His Lipase level was 54U/L (reference $<60 \mathrm{U} / \mathrm{L}$ ). He was admitted for three days and he improved with supportive care.

He underwent a repeat ERCP the following week for removal of the stent from the pancreatic duct (Episode D, Jan 2018). The biliary and pancreatic sphincterotomies appeared open and adequate. The thoughts at this stage were that should he develop a future episode of pancreatitis then minor papilla cannulation could be reattempted with a needle-knife sphincterotomy but this would entail a significant risk of pancreatitis.

He had a relatively good year but required further two admissions at the end of the year with mild pancreatitis (Episodes E, Nov 2018; Episode F, Dec 2018). He underwent an ERCP and underwent a free hand needle knife sphincterotomy of the minor papilla with no attempt at cannulating the minor duct of Santorini (Episode G, Feb 2019). The prior major papilla and biliary sphincterotomies were patent and the main pancreatic duct was trawled with a $4 \mathrm{~mm}$ balloon and nothing was found. A 5 French by $7 \mathrm{~cm}$ plastic pancreatic stent was placed in the main pancreatic duct.

He was admitted following this procedure with epigastric pain. He had a normal lipase level of $54 \mathrm{U} / \mathrm{L}$ (reference $<60 \mathrm{U} / \mathrm{L}$ ) and his LFTs were mildly deranged: Bilirubin $27 \mu \mathrm{mol} / \mathrm{L}$ (reference $<20 \mu \mathrm{mol} / \mathrm{L}$ ), ALT 70 (reference $<45 \mathrm{U} / \mathrm{L}$ ), AST 37 (reference $<35 \mathrm{U} / \mathrm{L}$ ) and GGT 126 (reference <55 U/L). A CT was performed which showed no evidence of perforation, the stent appeared to be unchanged and in position with some dilatation of the minor duct at $3.5 \mathrm{~mm}$. It also showed some minimal peripancreatic fat stranding surrounding the coeliac trunk suggesting pancreatitis. He was discharged the next day after his pain had settled.

He underwent an upper gastrointestinal endoscopy two weeks later to have his plastic pancreatic stent removed (Episode H, March 2019). The previous sphincterotomies were patent with free flow of bile. The previous free hand needle knife sphincterotomy was inspected with a possible small amount of clear fluid seen emanating from it but a decision was made not to cannulate it due to a possible connection with the main pancreatic duct as previously described on the CT.

Over the following six months, the patient had two brief admissions for pancreatitis (Episodes I, July 2019; J, Aug 2019). A CT scan during the second admission revealed acute pancreatitis with peripancreatic stranding. A follow-up MRCP a month later revealed complete resolution of his pancreatitis with stable biliary dilatation, and slight increase in the size of the main pancreatic duct to $5 \mathrm{~mm}$ (Episode K, Sept 2019).

After four months, the patient had a further admission for mild pancreatitis (Episodes L, Jan 2020). Following this episode, he had further investigation with an endoscopic ultrasound which showed changes within the pancreatic parenchyma of moderate chronic pancreatitis (Episode M, Feb 2020). There was mucin exuding from the minor papilla with hyperechoic material within the duct of Santorini suggestive of mucin (Fig. 4). These findings raised concern that he may also have an intraductal papillary mucinous neoplasm (IPMN) that was slowly enlarging and contributing to his recurrent pancreatitis.

Unfortunately, he went on to have three further brief 2 to 3-day admissions the same month for mild pancreatitis (Episodes N, Feb 2020). An ERCP and spyglass was performed following resolution of his pancreatitis the following month (Episode O, March 2020). Both pancreatic and biliary sphincterotomies were open. A mucin globule within the pancreatic duct was cleared with flushing. A spyscope into the pancreatic duct was performed with visualisation of mucin and dilated branches in the pancreatic head. Papillary projections were seen in the head and neck area of the pancreas but could not be advanced due to angulation at the neck of the pancreas (Fig. 5). Given these latest findings of IPMN contributing to his recurrent pancreatitis, and progressive dilatation of 


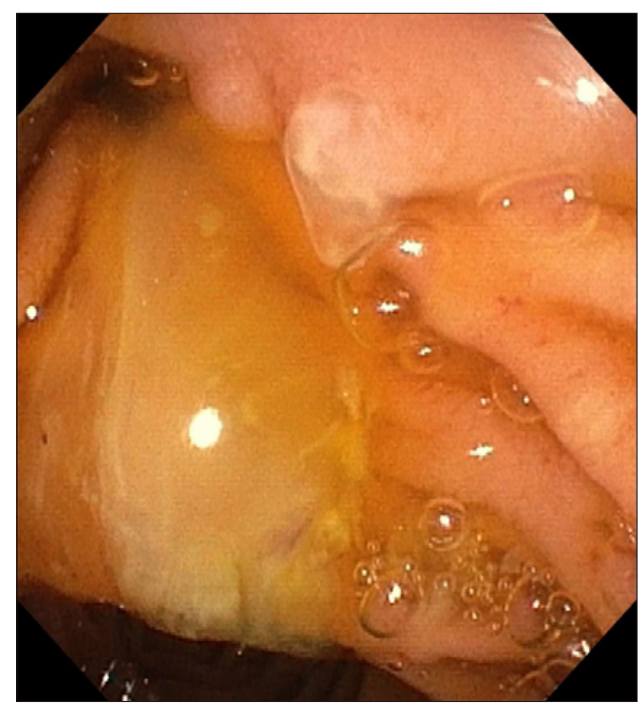

Fig. 4. Mucin seen exuding the minor papilla at endoscopy.

his main pancreatic duct over the course of his illness, surgical management with a pancreaticoduodenectomy has been considered which the patient agreeing to proceed with this in due course. He has remained well following his recent ERCP at time of publication of this article.

\section{DISCUSSION}

The formation of the hepatobiliary system begins in the fourth week of gestation as a ventral outgrowth of the caudal foregut. The hepatic diverticulum develops into two entities; the primordium of the liver and the primordium of the gallbladder and cystic duct complex. Thereafter, the gallbladder bud continues to develop in attachment with bile duct. In the seventh week of gestation, vacuolisation of the gallbladder and the cystic duct leads to the development of luminal surfaces. ${ }^{1,2}$ Aberration of this developmental process results in various forms of gallbladder agenesis. ${ }^{1}$ Hepatic diverticulum may fail to develop an outgrowth of the gallbladder. The gallbladder itself may fail to vacuolise to become atretic. Moreover, the gallbladder may appear absent due to inappropriate migration of the gallbladder primordium; subsequently resulting in ectopic gallbladder that may be located in intrahepatic space. ${ }^{3,4}$

Gallbladder agenesis is a rare condition that was first described by Lemery in the early $18^{\text {th }}$ century. ${ }^{5}$ In the general population, the incidence of gallbladder agenesis ranges between $0.01 \%$ to $0.065 \%$ with women three times

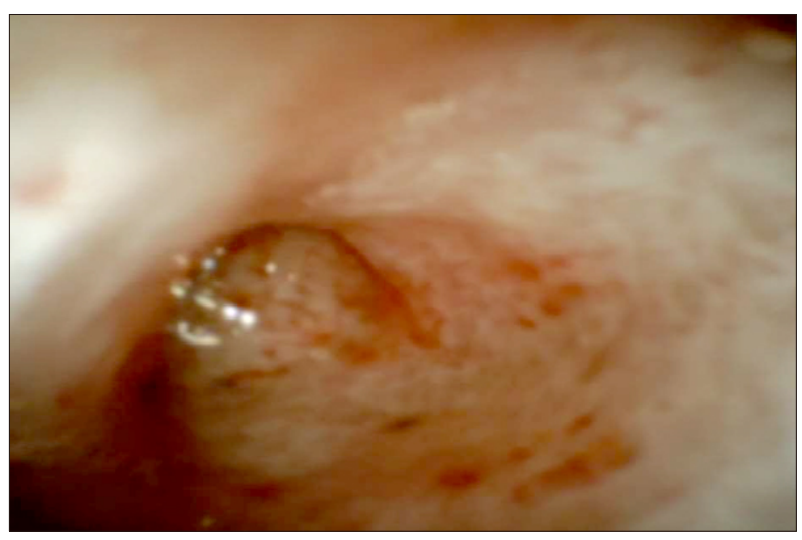

Fig. 5. Spyglass view of main pancreatic duct.

more likely to be affected than men. ${ }^{6}$ With variable clinical presentations observed with gallbladder agenesis, Bennion et al. ${ }^{7}$ classified the disorder into three categories of which $50 \%$ are symptomatic, $35 \%$ are asymptomatic, and $15 \%$ are associated with congenital anomalies such as renal agenesis, pancreatic divisum, duodenal atresia, imperforate anus, and cardiac septal defects.,

The symptomatic group typically mimics biliary colic with presentations of right hypochondrial pain, jaundice, dyspepsia, nausea, or fatty food intolerance. ${ }^{4}$ As a result, this makes the clinical diagnosis of gallbladder agenesis rather difficult. The pathophysiology of biliary colic in these patients has been contrasted to patients with post-cholecystectomy syndrome in whom the bile duct dilates to act as a substitute for bile storage in the absence of the gallbladder. ${ }^{1}$ Consequent increased biliary pressure against the sphincter of Oddi predisposes to biliary dyskinesia with subsequent sequalae of biliary stasis, infection, and choledocholithiasis. ${ }^{4-6}$

Given that gallbladder agenesis is a rare condition that is often indistinguishable from other more common biliary conditions, there are difficulties in making this accurate diagnosis pre-operatively. This can result in patients undergoing a planned cholecystectomy only to discover they have no gallbladder at time of surgery. Increased awareness of this condition along with utilisation of current imaging modalities will enable accurate diagnosis. ${ }^{4,5}$ In our patient, the diagnosis of gallbladder agenesis was confirmed with CT cholangiogram and MRCP with no need for exploratory procedures.

We hypothesise that our patient's recurrent acute pancreatitis may be attributed to the gallbladder agenesis, in 
combination with ansa pancreatica and Santorinicoele. The absence of the gallbladder on the MRCP was accompanied by dilation of the CBD. This finding was consistent with the hypothesis that gallbladder agenesis mimics post-cholecystectomy syndrome where the bile ducts dilate to act as a substitute for storage of the bile. The subsequent increase in biliary pressure against the sphincter of Oddi predisposes to biliary dyskinesia and stasis which was clinically evident with jaundice and the obstructive derangement in the liver function tests. This was compounded by the presence of ansa prancreatica which further impairs drainage of the main pancreatic duct through its spiral course to terminate in the more narrow calibre minor papilla. This explains the overall clinical presentations of recurrent acute pancreatitis.

In addition to the gallbladder agenesis and ansa pancreatica, this case was complicated by another anomaly that was seen on the MRCP - a Santorinicoele. This was evident as a focal dilatation of the proximal minor accessory pancreatic duct of Santorini and it remained dilated and appeared cystic despite resolution of the pancreatitis.

Santorinicoele was first described in 1994 by Eisen et al. ${ }^{8}$ who reported four cases of recurrent pancreatitis and pancreas divisum in the setting of focal cystic dilatations of the terminal portion of the dorsal pancreatic duct (duct of Santorini). It has been proposed that santorinicoele arises from a combination of weakness and obstruction of the ductal wall. ${ }^{8}$ However, its aetiopathogenesis has continued to be controversial as to whether it is a congenital or an acquired anomaly. Its relatively increased occurrence in the elderly population in association with acquired duodenal diverticula indicate an acquired aetiology. ${ }^{8-10}$ However, santorinicoele has also been reported in paediatric patients which suggests a potential congenital aetiology. ${ }^{11,12}$

Since its initial description, santorinicoele have mostly been reported in conjunction with pancreas divisum, either incomplete or complete. ${ }^{9,10,13-15}$ As a result, it has been assumed that santorinicoele is a result of pancreas divisum; in which, an obstruction of pancreatic outflow via the minor duodenal papilla with subsequent increase in ductal pressure predisposes to the formation of a santorinicoele. ${ }^{16}$ However, to the best of our knowledge, to date, there have been six cases of santorinicoele without pancreas divisum. ${ }^{16,17}$ Gonoi et al. (2013) ${ }^{17}$ conducted a cross-sec- tional study to report five cases of the above and were able to conclude that the santorinicoele is not always accompanied by pancreas divisum. They further established that such entity is most common in patients who suffer from pancreatitis, especially chronic pancreatitis; suggesting that santorinicoele may be an acquired pathology.

In addition, the presence of santorinicoele has been suggested to be a potential cause of the relative stenosis of the accessory papilla. ${ }^{18}$ This is associated with the possibility of the intraductal pressures to rise and trigger recurrent episodes of acute pancreatitis. ${ }^{18}$ As such, a balloon dilatation or sphincterotomy is understood as an effective management option in these patients with santorinicoele and pancreatitis by way of decreasing the intraluminal ductal pressures. $9,10,13,15$

In the case of our patient, an ERCP was performed with the aim of prevention of acute recurrent pancreatitis. The major papilla pancreatic sphincterotomy was performed with stent placement in the main pancreatic duct. The minor papilla was also identified with the santorinicoele that was characterised by a bulge in the region. However, cannulation of the minor papilla was unsuccessful at initial ERCP due to the relative stenosis of the minor papilla. Given development of further episodes of pancreatitis, needle-knife sphincterotomy of the minor papilla was performed. The patient has had no further episodes of pancreatitis in the four months post-procedure but unfortunately developed recurrent attacks with ultimate findings of IPMN.

It is difficult to conclude whether the santorinicoele developed through an acquired pathway or aetiology secondary to the gallbladder agenesis and ansa pancreatica which may have contributed to the development of the santorinicoele in our patient. It is understood that gallbladder agenesis, which results in bile duct dilatation and increased pressure on sphincter of Oddi, causes biliary dyskinesia and stasis. Consequently, this reduces the excretion of the bile and pancreatic fluids and therefore increases the overall pressure within the pancreatic ducts. Our hypothesis is that this resultant intraductal increase in pressure from congenital gallbladder agenesis, may have contributed to the formation of the santorinicoele.

This is the first case that describes recurrent acute pancreatitis in the setting of gallbladder agenesis, ansa pancreatica and Santorinicoele without pancreatic divisum. 
These rare anatomical variants have been described to result in pancreatitis in their own respective ways. The common finding with these variants is that they hinder adequate excretion of bile and pancreatic juice through their respective mechanisms; ultimately resulting in recurrent acute pancreatitis from raised intraductal pressure.

\section{ORCID}

Sun Woo Lee: https://orcid.org/0000-0003-2654-0294

Caroline Jane Davidson:

https://orcid.org/0000-0003-0111-2488

YinHiew Kia: https://orcid.org/0000-0003-4234-2888

Ben Devereaux: https://orcid.org/0000-0003-1795-5690

Savio Godinho: https://orcid.org/0000-0003-3743-8850

Mark Appleyard: https://orcid.org/0000-0003-2714-8657

Nicholas O'Rourke:

https://orcid.org/0000-0003-0744-2816

Manju Dashini Chandrasegaram:

https://orcid.org/0000-0002-4826-5038

\section{REFERENCES}

1. Bani-Hani KE. Agenesis of the gallbladder: difficulties in management. J Gastroenterol Hepatol 2005;20:671-675.

2. Bedi N, Bond-Smith G, Kumar S, Hutchins R. Gallbladder agenesis with choledochal cyst--a rare association: a case report and review of possible genetic or embryological links. BMJ Case Rep 2013;2013:bcr2012006786.

3. Yoldas O, Yazıc1 P, Ozsan I, Karabuga T, Alpdogan O, Sahin $\mathrm{E}$, et al. Coexistence of gallbladder agenesis and cholangiocarcinoma: report of a case. J Gastrointest Surg 2014;18:13731376.

4. Malde S. Gallbladder agenesis diagnosed intra-operatively: a case report. J Med Case Rep 2010;4:285.

5. Rajkumar A, Piya A. Gall bladder agenesis: a rare embryonic cause of recurrent biliary colic. Am J Case Rep 2017;18:334338.

6. Kosmidis CS, Koimtzis GD, Kosmidou MS, Ieridou F, Koletsa $\mathrm{T}$, Zarampouka KT, et al. Gallbladder hypoplasia, a congenital abnormality of the gallbladder: a case report. Am J Case Rep 2017; 18:1320-1324.

7. Bennion RS, Thompson JE Jr, Tompkins RK. Agenesis of the gallbladder without extrahepatic biliary atresia. Arch Surg 1988; 123:1257-1260.

8. Eisen G, Schutz S, Metzler D, Baillie J, Cotton PB. Santorinicele: new evidence for obstruction in pancreas divisum. Gastrointest Endosc 1994;40:73-76.

9. Costamagna G, Ingrosso M, Tringali A, Mutignani M, Manfredi R. Santorinicele and recurrent acute pancreatitis in pancreas divisum: diagnosis with dynamic secretin-stimulated magnetic resonance pancreatography and endoscopic treatment. Gastrointest Endosc 2000;52:262-267.

10. Seibert DG, Matulis SR. Santorinicele as a cause of chronic pancreatic pain. Am J Gastroenterol 1995;90:121-123.

11. Khan SA, Chawla T, Azami R. Recurrent acute pancreatitis due to a santorinicele in a young patient. Singapore Med J 2009;50: e163-e165.

12. Tang H, Kay CL, Devonshire DA, Tagge E, Cotton PB. Recurrent pancreatitis in a child with pancreas divisum. Endoscopic therapy of a Santorinicele. Surg Endosc 1999;13:1040-1043.

13. Peterson MS, Slivka A. Santorinicele in pancreas divisum: diagnosis with secretin-stimulated magnetic resonance pancreatography. Abdom Imaging 2001;26:260-263.

14. Manfredi R, Costamagna G, Brizi MG, Spina S, Maresca G, Vecchioli A, et al. Pancreas divisum and "santorinicele": diagnosis with dynamic MR cholangiopancreatography with secretin stimulation. Radiology 2000;217:403-408.

15. Joo KR, Bang SJ, Shin JW, Kim DH, Park NH. Santorinicele containing a pancreatic duct stone in a patient with incomplete pancreas divisum. Yonsei Med J 2004;45:952-955.

16. Byeon JS, Kim MH, Lee SK, Yang DH, Bae JS, Kim HJ, et al. Santorinicele without pancreas divisum. Gastrointest Endosc 2003;58:800-803.

17. Gonoi W, Akai H, Hagiwara K, Akahane M, Hayashi N, Maeda E, et al. Santorinicele without pancreas divisum pathophysiology: initial clinical and radiographic investigations. BMC Gastroenterol 2013;13:62.

18. Nam KD, Joo KR, Jang JY, Kim NH, Lee SK, Dong SH, et al. A case of santorinicele without pancreas divisum: diagnosis with multi-detector row computed tomography. J Korean Med Sci $2006 ; 21: 358-360$. 